\title{
Knowledge, Attitude and Practice of Adverse Pregnancy Outcomes Prevention among Women of Reproductive Age in Nasarawa Local Government Area, Kano State, Nigeria
}

\author{
Ismail Bamidele Afolabi ${ }^{*}$, Aremu AbdulMujeeb Babatunde ${ }^{2}$, Salaam Mujeeb², \\ Shamsuddeen Suleiman Yahaya ${ }^{3}$, Ada Abaku ${ }^{4}$, Ngozi Jane Muonagolu² \\ ${ }^{1}$ Faculty of Science and Technology, Department of Public Health, Cavendish University, Kampala, Uganda \\ ${ }^{2}$ Faculty of Health Sciences, Islamic University in Uganda, Kampala Campus, Kampala, Uganda \\ ${ }^{3}$ Katsina State Primary Health Care Agency, Katsina, Nigeria \\ ${ }^{4}$ Department of Chemical Pathology, University of Port Harcourt Teaching Hospital, University of Port Harcourt, Port Harcourt, Nigeria \\ Email: harforly@gmail.com
}

How to cite this paper: Afolabi, I.B., Babatunde, A.A., Mujeeb, S., Yahaya, S.S., Abaku, A. and Muonagolu, N.J. (2021) Knowledge, Attitude and Practice of Adverse Pregnancy Outcomes Prevention among Women of Reproductive Age in Nasarawa Local Government Area, Kano State, Nigeria. Open Journal of Epidemiology, 11, 501-516. https://doi.org/10.4236/ojepi.2021.114040

Received: July 19, 2021

Accepted: November 27, 2021

Published: November 30, 2021

Copyright $\odot 2021$ by author(s) and Scientific Research Publishing Inc. This work is licensed under the Creative Commons Attribution International License (CC BY 4.0).

http://creativecommons.org/licenses/by/4.0/ (c) (i) Open Access

\begin{abstract}
Background: Adverse pregnancy outcomes continue to contribute substantially to maternal mortality as well as poor maternal and fetal health outcomes whose burden can be reduced by the initiation of preventive behaviors like the uptake of maternal health services. This continuous unacceptably high maternal mortality justifies a need for progressive research to better understand the predictors of the preventive behaviors of women towards adverse pregnancy outcomes. This study was conducted to assess levels of knowledge, attitudes about adverse pregnancy outcomes and preventive practices among women of reproductive age in Nassarawa local government area, Kano State, Nigeria. Methodology: The study was a cross-sectional descriptive study that employed a four-sectioned pretested researcher administered questionnaire to collect data on knowledge, attitude and practice of adverse pregnancy outcomes prevention among 164 consenting respondents in Kano State, Nigeria between November 2020 and December 2020. Responses were transformed and computed using SPSS version 26 to generate descriptive statistics. Regression analysis was done to test the degree of association between the predictors and practice of adverse pregnancy outcomes prevention with the level of significance set at a cut-off of $\mathrm{p} \leq 0.05$. Results: The findings showed that the majority of the respondents were between 20 - 24 years of age and had secondary educational attainment. Results further revealed that knowledge and attitude about adverse pregnancy outcomes which were both measured on 18-point scales, reported for the respondents' mean scores of $9.46(9.07 \pm 9.85)$ and $10.72(9.79 \pm 10.62)$ respec-
\end{abstract}


tively. The practice of adverse pregnancy outcomes prevention when assessed on a 15-point scale shows that respondents scored a mean of $7.42 \pm 8.30$ which denotes $53.4 \%$ of the level of prevention practice anticipated from the respondents. The study also showed a significant positive association between the level of knowledge $(\mathrm{p}=0.010)$, attitude $(\mathrm{p}<0.001)$ and prevention practice of adverse pregnancy outcomes. Conclusions: The findings reported an average but inadequate knowledge and neutral attitude that predicted unsatisfactory adverse pregnancy outcomes prevention practices among the examined reproductive-aged women, which calls for targeted health education on adverse pregnancy outcomes within the community in order to inform better prevention practices.

\section{Keywords}

Knowledge, Attitudes, Preventive Behavior, Adverse Pregnancy Outcomes

\section{Background}

Adverse pregnancy outcomes are significant health challenges for women in the periconceptional period as well as infants. These include pregnancy bleeding, hypertensive disorders and sepsis, which lead to more than half of the maternal deaths [1]. It is estimated by the World Health Organization that every day more than 830 women die from pregnancy and or childbirth-related complications around the globe [2] and in 2015 alone, approximately 303,000 women died during and following pregnancy and childbirth [3].

The adverse pregnancy outcomes such as stillbirths, miscarriages, abortions and preterm births are globally being used as maternal health indices [4]. More than $60 \%$ of preterm births take place in South Asia and sub-Saharan Africa [5] where it is also estimated that about 14.9 million preterm infants are born every year, accounting for $11.1 \%$ of live births, and more than half of them are born in Asian and African countries where Nigeria predominantly belongs to [6]. Similarly, abortions and stillbirths are common adverse pregnancy outcomes that contribute substantially to poor maternal health outcomes. Reports had previously shown that among an estimated 210 million pregnancies, 75 million ended in abortion or stillbirth [7] [8].

There is a vast deviation in pregnancy outcomes between high-income and many middle- and low-income countries, as in the majority of low-income countries, the maternal mortality ratio is 100 -fold higher than those reported in high-income countries regardless of whether both mother and infant survive, pregnancy complications or problems at delivery or during the neonatal period can lead to severe maternal or infant morbidity [9] and this disparity in adverse pregnancy outcomes in low-income countries is attributed to poor antenatal care received by women in low-income countries [10]. According to the World Health Organization (WHO), Nigeria had the highest estimated number of maternal deaths in Africa, and ranked eighth in the sub-Saharan region behind Angola, Chad, Liberia, Niger, Rwanda, 
Sierra Leone and Liberia [11]. Approximately 75 percent $(27,750)$ of these maternal deaths are attributable to direct obstetric complications, such as infection, toxemia, and unsafe induced abortion. In Northern Nigeria, eclampsia has been reported as the leading cause of maternal mortality [12]. This is attributed to cultural practices leading to early childbearing in the wake of poor maternity care services that are grossly underutilized. In a previous report from Maiduguri, Northeastern Nigeria, eclampsia accounted for $46.4 \%$ of all maternal deaths [12] [13]. Women who receive prenatal care or preconception care (PCC) are appropriately screened for conditions like, diabetes, hypertension, anemia, Rhesus disease, and syphilis, and they are appropriately treated, therefore, as a result, they tend to have reduced rates of stillbirth, neonatal and maternal mortality [14].

The evidence increasingly points to preconception care before pregnancy to improve women's health, and better pregnancy outcomes for the mother and newborn. However, if women are not adequately informed about the risk factors associated with adverse pregnancy outcomes and if they display poor attitudes toward preventing themselves and their babies against these negative maternal health outcomes, they are not likely to uptake preconception care and embark on practices that will prevent them from the risk of these outcomes as similar studies have also shown that [15] [16] [17]. Adverse pregnancy outcomes are influenced by a myriad of biological, social and environmental factors. Numerous studies have found that socioeconomic status and income inequality are correlated with birth outcomes. A variety of other social factors have been linked to poor birth outcomes, including maternal education, marital status, pregnancy intention and teenage pregnancy [18]. Other factors such as maternal obesity, maternal comorbidities and genetic vulnerabilities have also been linked to poor pregnancy outcomes [19].

Therefore, it is necessary to adopt preventive measures to control and relieve the occurrence of these adverse outcomes. Primary prevention including specific practices of health promotion, protective procedures, detection and regulation of environmental pollutants is considered as an essential way for adverse pregnancy outcomes remission.

Previous studies have demonstrated that about $70 \%$ of adverse pregnancy outcomes such as birth defects are effectively prevented or cured with proper care [20]. One critical step for the primary prevention practice is to investigate the knowledge of adverse pregnancy outcomes risk factors and attitudes in relation to practices of reproductive age women toward the prevention of adverse pregnancy outcomes. This study, however, assessed knowledge of risk factors and attitudes as the predictors of adverse pregnancy outcomes prevention practices among reproductive-aged women in Nasarawa Local Government Area (LGA) in Kano State, Nigeria.

\section{Method}

\subsection{Study Design}

The study was a descriptive cross-sectional study that employed quantitative da- 
ta collection method that helped in determining the predictors of Adverse Pregnancy Outcomes (APO) prevention practices among reproductive age women in Nasarawa Local Government Area (LGA) in Kano State, Nigeria.

\subsection{Location}

This study was conducted in Nasarawa Local Government Area of Kano State in the North-West of Nigeria which is administratively divided into 44 Local Government Areas (LGAs). It is the most populous northern state with a total population of 9.4 million people of which 4,627,556 (48.3\%) are female [21]. Women of childbearing age (15 - 49 years) account for about one-fifth of the total population and Nasarawa Local Government Area in Kano State, Nigeria has an area of $34 \mathrm{~km}^{2}$ and a population of 678,669 as at the last census in Nigeria.

\subsection{Sample Size Estimation}

The study involved a total of 164 respondents from Nasarawa LGA estimated using Kish Leslie formula (1965) based on the proportion of $18.6 \%$ adverse birth outcomes reported in a previous study conducted within Sub-Saharan Africa by Tsegaye and Kassa [22], a precision of 0.05 , type 1 error (alpha) of $10 \%$.

$$
\begin{gathered}
N=\frac{Z \alpha^{2}(1-P)}{d^{2}} \\
N=\frac{1.645^{2} \times(0.186 \times 0.814)}{0.05^{2}}
\end{gathered}
$$

where $N$ = sample size estimate of women of reproductive age;

$P=$ reported true population proportion of adverse birth outcomes (18.6\%);

$Z \alpha=$ Standard normal deviate at $90 \%$ confidence interval corresponding to 1.645 ;

$D=$ Maximum acceptable error of $5 \%$.

\subsection{Sampling Procedures}

This study employed systematic random sampling in selecting households in the Local Government Area and eligible consenting women of reproductive age found in selected households were included in the study.

\subsection{Inclusion Criteria and Exclusion Criteria}

The study included every consenting women of reproductive age in the selected households in the Local Government Area and excluded all eligible women of reproductive age who did not give their consent to participate in the study. Those who were severely ill to participate in the study related procedures were also excluded.

\section{Variables and Test of Significance}

\subsection{Independent Variables}

The independent variables measured include the socio-demographic characte- 
ristics measured categorically, the level of knowledge of adverse pregnancy risk factor and attitudes towards prevention of adverse pregnancy outcomes which are both measured on 18 point reference scales using a 4-point Likert scale responses of "strongly agree", "agree", "disagree" and "strongly disagree".

\subsection{Dependent Variables}

The dependent variable measured was Adverse Pregnancy Outcomes (APO) prevention practices among women of reproductive age in the study area on a 4point Likert scale responses of "not at all", "rarely", "occasionally" and "very often".

\subsection{Data Collection, Processing and Analysis}

Quantitative data was obtained using a four-sectioned pretested researcher administered questionnaire to capture data on the study variables. Research assistants were recruited to capture the data having undergone training on the study specific procedures. The data were cleaned sorted and the responses from the $\mathrm{Li}$ kert scales were transformed by computation on SPSS version 26 to generate descriptive statistics such as mean scores for the levels of the variables and reported by prevalence. Regression analysis was then employed to test the degree of association between the predictors and adverse pregnancy outcomes prevention practices and test of significance was being set at $5 \%$ cut-off.

\subsection{Ethical Consideration}

Ethical approval to conduct the study was obtained from the local health authority at the Local Government Area. Explanation of the purpose, risks and benefits of the study was provided to the participants before soliciting for their participation in the study, Confidentiality was attached to the storage of the data collected from the field and no disclosure was made without any prior approval of the respondents.

\section{Results}

\subsection{Socio-Demographic Characteristics of the Respondents}

The findings from this study on the demographic characteristics of the study respondents showed that among the total 164 participants majority $60(36.6 \%)$ were between the age of 20 - 24 years, majority of them 143/164 (87.1\%) were married. Regarding the educational attainment majority 46 (28.1\%) of the respondents had secondary education and more than three-quarters 151 (92.1\%) of the respondents religious wise reported to be Muslim (see Table $1)$.

\subsection{Knowledge on the Risk Factors Influencing Adverse Pregnancy Outcomes}

The findings regarding the knowledge on risk factors influencing adverse pregnancy 
Table 1. Showing demographic characteristics of the respondents $\mathrm{N}=164$.

\begin{tabular}{|c|c|c|c|}
\hline \multicolumn{2}{|c|}{ Variables } & \multirow{2}{*}{$\begin{array}{c}\text { Frequency }(\mathrm{N}) \\
24\end{array}$} & \multirow{2}{*}{$\begin{array}{c}\text { Percentage (\%) } \\
14.6\end{array}$} \\
\hline Age & $15-19$ & & \\
\hline & $20-24$ & 60 & 36.6 \\
\hline & $25-29$ & 42 & 25.6 \\
\hline & $30-34$ & 25 & 15.3 \\
\hline & 35 and above & 13 & 7.9 \\
\hline \multirow[t]{3}{*}{ Marital status } & Married & 143 & 87.1 \\
\hline & Divorced & 15 & 9.1 \\
\hline & Widowed & 6 & 3.8 \\
\hline \multirow[t]{5}{*}{ Educational attainment } & Non-formal & 29 & 17.7 \\
\hline & Primary & 35 & 21.3 \\
\hline & Secondary & 46 & 28.1 \\
\hline & Vocational & 23 & 14.0 \\
\hline & University & 31 & 18.9 \\
\hline \multirow[t]{3}{*}{ Religion } & Islam & 151 & 92.1 \\
\hline & Christianity & 10 & 6.1 \\
\hline & Others & 3 & 1.8 \\
\hline
\end{tabular}

outcomes reveals that majority of the respondents 55 (33.5\%) strongly disagreed that malnutrition in pregnancy could result in smallness of the baby abortion or other congenital disorders and less than half of them 33(20\%) strongly disagreed that pregnancy at younger age below 15 years do not often result in having children with developmental disabilities and pose risk of caesarean section at birth. Regarding pre-natal care, majority 54 (32.9\%) of the respondents strongly agreed that inadequate pre-natal care would cause death of the mother due to difficulties during delivery, similarly, nearly two-third of the participants (37.8\%) strongly agreed that alcohol consumption cannot lead to reduced birth size of the baby. Where 51 (31.1\%) strongly disagreed that inadequate maternal education can result in poor deliveries only half of them 58 (35.4\%) agreed strongly that drug abuse at early stage of pregnancy results to brain damage of the baby (refer to Table 2).

\subsection{Attitudes toward Adverse Pregnancy Outcomes Prevention Practices}

The study findings regarding attitude towards adverse pregnancy outcomes prevention practices demonstrated that half of the respondents 50 (30.5\%) strongly agreed that they do not see anything wrong in being pregnant every year or in quick succession, similarly almost two-third of the respondents 64 (39.1\%) strongly agreed that they are willing to readily undergo caesarean section if need be in order to avoid complications during delivery. More so, 48 (29.3\%) of them strongly agreed that their culture does not see anything wrong in having children as 
early as age 15. Nearly two-third of the respondents 65 (39.6\%) strongly agreed that they do not think going for antenatal checkup is necessary and hence they have their babies in the church or mosque. Where majority of them 52 (31.7\%) do not see the need for education as a factor for safe delivery similar number 52 (31.7\%) also have problem taking folic acid before and during pregnancy as recommended (see Table 3).

\subsection{Adverse Pregnancy Outcomes Prevention Practices}

The prevention practices of respondents towards adverse pregnancy outcomes showed that majority of the respondents 65 (39.6\%) avoid going for antenatal care at the health centers very often whenever they are pregnant similarly, majority of them $57(34.8 \%)$ do not at all attend health education and awareness

Table 2. Knowledge on the risk factors influencing adverse pregnancy outcomes $\mathrm{N}=164$.

\begin{tabular}{|c|c|c|c|c|}
\hline Statements for consideration & SA & A & $\mathrm{D}$ & SD \\
\hline Malnutrition in pregnancy could result in smallness & 35 & 42 & 32 & 55 \\
\hline of the baby, abortion or other disorders & $21.3 \%$ & $25.6 \%$ & $19.5 \%$ & $33.5 \%$ \\
\hline \multirow{2}{*}{$\begin{array}{l}\text { Pregnancy at younger age below } 15 \text { years do not often } \\
\text { result in having children with developmental } \\
\text { disabilities and pose risk of caesarean section at birth }\end{array}$} & 48 & 47 & 36 & 33 \\
\hline & $29.3 \%$ & $28.7 \%$ & $22.0 \%$ & $20 \%$ \\
\hline \multirow{2}{*}{$\begin{array}{l}\text { Inadequate pre-natal care would cause death of the } \\
\text { mother due to difficulties during delivery }\end{array}$} & 54 & 41 & 32 & 37 \\
\hline & $32.9 \%$ & $25.0 \%$ & $19.5 \%$ & $22.6 \%$ \\
\hline \multirow{2}{*}{$\begin{array}{l}\text { Alcohol consumption cannot lead to reduced birth } \\
\text { size of the baby }\end{array}$} & 62 & 36 & 40 & 26 \\
\hline & $37.8 \%$ & $22.0 \%$ & $24.4 \%$ & $15.8 \%$ \\
\hline \multirow{2}{*}{$\begin{array}{l}\text { Inadequate maternal education can result in poor } \\
\text { deliveries }\end{array}$} & 30 & 38 & 45 & 51 \\
\hline & $18.3 \%$ & $23.2 \%$ & $27.4 \%$ & $31.1 \%$ \\
\hline \multirow{2}{*}{$\begin{array}{l}\text { Drug abuse at early stage of pregnancy can result in } \\
\text { brain damage of the baby }\end{array}$} & 58 & 45 & 32 & 29 \\
\hline & $35.4 \%$ & $27.4 \%$ & $19.5 \%$ & $17.7 \%$ \\
\hline
\end{tabular}

Table 3. Attitudes toward adverse pregnancy outcomes prevention practices $\mathrm{N}=164$

\begin{tabular}{lllll}
\hline Statements for consideration & SA & A & D & SD \\
\hline There is nothing wrong in being pregnant every & 50 & 49 & 29 & 36 \\
year or in quick succession & $30.5 \%$ & $29.8 \%$ & $17.7 \%$ & $22.0 \%$ \\
In order to avoid complications during delivery if & 64 & 45 & 21 & 34 \\
need be, I will readily undergo Caesarean section & $39.1 \%$ & $27.4 \%$ & $12.8 \%$ & $20.7 \%$ \\
My culture does not see anything wrong in having & 48 & 40 & 35 & 41 \\
children as early as age 15 & $29.3 \%$ & $24.4 \%$ & $21.3 \%$ & $25.0 \%$ \\
I do not think going for antenatal checkup is necessary & 65 & 44 & 30 & 25 \\
hence I have my babies in the church or mosque & $39.6 \%$ & $26.8 \%$ & $18.3 \%$ & $15.3 \%$ \\
I do not see the need for education as a factor for & 52 & 48 & 33 & 31 \\
safe delivery & $31.7 \%$ & $29.3 \%$ & $20.1 \%$ & $18.9 \%$ \\
I do not have any problem as regards taking folic & 25 & 39 & 48 & 52 \\
acid before and during pregnancy as recommended & $15.2 \%$ & $23.8 \%$ & $29.3 \%$ & $31.7 \%$ \\
\hline
\end{tabular}


programs regarding maternal health in the community and clinic. Where almost three-quarter of the respondents $72(43.9 \%)$ do not consume alcohol before and during pregnancy only 51 (31.1\%) of them rarely avoid taking drug without prescription during pregnancy and lastly regarding practice of folic acid supplementation during pregnancy, more than half of the total respondents $88(53.7 \%)$ do not take folic acid as recommended during pregnancy (refer to Table 4).

The summaries of the descriptive statistics to establish the level of the variables in the study is displayed in Table 5 where the knowledge on the risk factors influencing adverse pregnancy outcomes among the study respondents measured on 18-point reference scale was found out to have a mean score of $9.46(\mathrm{CI}=9.07$ $\pm 9.85)$, SD of 2.52 which denoted a prevalence of $53 \%$, the level of attitudinal disposition among the respondents towards adverse pregnancy outcome prevention practices measured on 18-point reference scale has a mean score of 10.21 $(\mathrm{CI}=9.79 \pm 10.62)$, SD of 2.73 which represent $56.7 \%$ of the total level attitudinal disposition expected from the respondents. The level of prevention practices of the respondents towards adverse pregnancy outcomes as measured on 15-point reference scale is shown to have a mean score of 7.86 (CI $=7.42 \pm 8.30)$, SD of 2.90 which constitute of $53.4 \%$ of the complete prevention practices expected from the respondents.

Table 4. Adverse pregnancy outcomes prevention practices $\mathrm{N}=164$.

\begin{tabular}{|c|c|c|c|c|}
\hline Statements for consideration & NA & $\mathbf{R}$ & $\mathrm{O}$ & Vo \\
\hline \multirow{2}{*}{$\begin{array}{l}\text { I avoid going for antenatal care at the health } \\
\text { centers whenever I am pregnant }\end{array}$} & 19 & 38 & 42 & 65 \\
\hline & $11.6 \%$ & $23.2 \%$ & $25.6 \%$ & $39.6 \%$ \\
\hline \multirow{2}{*}{$\begin{array}{l}\text { I attend health education and awareness programs } \\
\text { regarding maternal health in the community and } \\
\text { clinic }\end{array}$} & 57 & 46 & 26 & 35 \\
\hline & $34.8 \%$ & $28.0 \%$ & $15.9 \%$ & $21.3 \%$ \\
\hline \multirow{2}{*}{ I do consume alcohol before and during pregnancy } & 72 & 50 & 24 & 18 \\
\hline & 43.99 & $30.5 \%$ & $14.6 \%$ & $11.0 \%$ \\
\hline \multirow{2}{*}{$\begin{array}{l}\text { I avoid taking drug without prescription during } \\
\text { pregnancy }\end{array}$} & 43 & 51 & 34 & 36 \\
\hline & $26.2 \%$ & $31.1 \%$ & $20.7 \%$ & $22.0 \%$ \\
\hline \multirow{2}{*}{$\begin{array}{l}\text { I am not used to taking Folic acid as recommended } \\
\text { during pregnancy to prevent unwanted pregnancy }\end{array}$} & 23 & 18 & 35 & 88 \\
\hline & $14.0 \%$ & $11.0 \%$ & $21.3 \%$ & $53.7 \%$ \\
\hline
\end{tabular}

Note: NA = "not at all", $\mathrm{R}=$ "rarely", $\mathrm{O}=$ "occasionally" and VO = "very often".

Table 5. Summaries of the descriptive statistics for respondents in this study.

\begin{tabular}{cccccc}
\hline Variable & $\begin{array}{c}\text { Maximum } \\
\text { score } \\
\text { on reference } \\
\text { scale }\end{array}$ & Mean & $\begin{array}{c}\text { Standard } \\
\text { deviation }\end{array}$ & & $\begin{array}{c}\text { Level } \\
\text { Confidence-Interval } \\
\text { (Prevalence) }\end{array}$ \\
\hline $\begin{array}{c}\text { Knowledge } \\
\text { Attitude }\end{array}$ & 18 & 9.46 & 2.52 & $9.07 \pm 9.85$ & $53 \%$ \\
$\begin{array}{c}\text { APO prevention } \\
\text { practices }\end{array}$ & 18 & 10.21 & 2.73 & $9.79 \pm 10.62$ & $56.7 \%$ \\
\hline
\end{tabular}




\subsection{Relationship between Knowledge, Attitude and the Prevention Practices of Adverse Pregnancy Outcomes}

This study report a significant positive relationship between knowledge level, level of attitudinal disposition and APO prevention practices with a correlation B coefficient of $0.040(p=0.010)$ and $0.060(p<0.001)$ respectively which shows that they both predict prevention practices of adverse pregnancy outcomes (see Table 6).

Table 6. Relationship between knowledge, attitude and APO prevention practices.

\begin{tabular}{ccccc}
\hline Variables & $\mathbf{B}$ & $\mathbf{R}^{2}$ & F-value & p-value \\
\hline & & 0.649 & 75.9 & \\
Knowledge & 0.40 & & & 0.010 \\
Attitude & 0.60 & & $<0.001$ \\
\hline
\end{tabular}

\section{Discussions}

This study captured data from 164 consenting women of reproductive age where majority of the respondents were between the age of 20 and 24 and had secondary educational attainment, Findings from this study on the general assessment of the level of knowledge of risk factors influencing adverse pregnancy outcomes showed that the respondents displayed an average but inadequate level of knowledge with a prevalence of 53\%, this is not in line with the low knowledge level reported in a cross-sectional study conducted by Li et al. [23] and also with that of Yang et al. [24]. Despite this average level of knowledge, majority of the respondents $55(33.5 \%)$ strongly disagreed that malnutrition in pregnancy could result in smallness of the baby abortion or other congenital disorders, a very poor knowledge of the effect of malnutrition that has implication for targeted health education regarding malnutrition as a risk factor of adverse pregnancy outcomes. This report is almost in concord with the report from the study of Eni-Olorunda et al. [17] and in contrast with the $80 \%$ study respondents displaying correct knowledge in the study conducted by Ibtehaj Alharbi et al. [25].

The less than half of this study respondents 33 (20\%) strongly disagreeing to the fact that pregnancy at younger age below 15 years often result in having children with developmental disabilities and pose risk of caesarean section at birth is almost in accordance with one-third of the respondents in the study of Ibtehaj Alharbi et al. [25] strongly agreeing to that and slightly opposite to just 28 respondents agreeing strongly to that in the study conducted in Abeokuta, Nigeria by [17]. This poor knowledge demonstrated by the respondents might be as a result of the prevailing culture of early childhood marriage in this region which also calls for continuous sensitization on the risk of adverse pregnancy from early childhood marriage. Regarding pre-natal care, half of the respondents strongly agreed that inadequate pre-natal care would cause death of the mother due to difficulties during delivery, a report similar to the findings from the study of Eni-Olorunda 
et al. [17], getting to know this fact by the respondents is encouraging and might have influence on them initiating prenatal care in order to avoid the risk of adverse pregnancy outcomes. More than one-third of our respondents (37.8\%) do not know the risk of alcohol consumption during pregnancy, a report not in accordance with the $11 \%$ respondents displaying similar poor knowledge in a previous study [17] and where relatively half of our respondents do not know that inadequate maternal education can result in poor deliveries only 58 (35.4\%) of them agreed strongly that drug abuse at early stage of pregnancy result to brain damage of the baby which is contrary to what Karlsen and Say [26] reported and that of Benegbi et al. [27]. Health education still has a lot of gaps to fill in this region on the knowledge of risk factors influencing adverse pregnancy outcomes in order to be able to have reduced burden of this health issue as it is evidently seen in this study that a better knowledge of the risk factors will influence the prevention practices of the respondents.

The findings from this study regarding attitudinal disposition of the respondents towards adverse pregnancy outcomes prevention practices showed that the respondents displayed a fairly positive and average attitude constituting $56.7 \%$ of the total level of attitudinal disposition expected of them. Furthermore, it was observed from this study that majority of the respondents strongly agreed that they do not see anything wrong in being pregnant every year or in quick succession, this is similar to what was reported by Eni-Olorunda et al. [17] and Bhalotra and Van Soest [28], however, contrary to this report was the report from the study of Ibtehaj Alharbi et al. [25] where more than half of their study respondents believed that being pregnant every year or in quick succession may compromise the mother. The report from this study and that of Eni-Olorunda and others [17] contradicts the recommendation of World Health Organization that there should be spacing of at least two to three years between births to reduce infant and child mortality and improve maternal health whereas, according to the Ghana Maternal Health Survey [29], childhood and maternal mortality is strongly associated with variations in birth intervals.

Similarly, almost two-third of the respondents in our study 64 (39.1\%) strongly agreed that they are willing to readily undergo caesarean section if need be in order to avoid complications during delivery, this is in accordance with the positive attitude displayed towards antenatal check up to ensure proper growth and development of the child as well as having a safe delivery among majority of the respondents in the study of Eni-Olorunda et al. [17] and the results concerning respondents attitude towards APO prevention practices in the study conducted by Ibtehaj Alharbi et al. [25] to determine the knowledge and attitude on risk factors influencing pregnancy outcomes in Saudi Arabia was in line with the report from this study and that of Eni-Olorunda and colleagues [17] where results of the statement about ANC was satisfactory with more than $80 \%$ agreement on the necessity of ANC check-up during pregnancy.

More so, nearly half of our study respondents strongly agreed that their cul- 
ture does not see anything wrong in having children as early as age 15 and this is line with the $30 \%$ of the total respondents in a previous similar study [17] that displayed similar attitude. This is a prevailing issue in the Northern Nigeria that needs to be addressed to change the perception of women towards early childhood marriage. The findings that two-third our respondents strongly agreed that they do not think going for antenatal checkup is necessary and hence they have their babies in the church or mosque is contrary to the findings of Eni-Olorunda and colleagues [17]. This calls for health education on the importance of Antenatal checkup during pregnancy, otherwise, this vulnerable population group will keep predisposing themselves to the risk of Adverse pregnancy outcomes. The findings that majority of our respondents do not see the need for education as a factor for safe delivery and also having problem taking folic acid before and during pregnancy as recommended is a report similar to the reports from the study of Temel et al. [30] and Li et al. [23]. This implies that maternal education is given no priority in this region and may hamper any intervention geared towards reducing the magnitude of adverse pregnancy outcomes. The unsatisfactory practices of adverse pregnancy outcomes prevention reported in this study is almost in line with the good practices especially regarding folic acid supplementation reported in the study of Li et al. [23] which assessed the attitude of women towards APO prevention practices and concluded that most women are clear regarding the importance of folic acids. Similar results were also found in America and Denmark as reported by Olsen and Knudsen [31] and Temel et al. [30]. However, the study of Li et al. [23] in line with previous studies suggested that lower correct rate of FA supplementation (including starting time and supplementary dose) was consistent with lower knowledge, the report that necessitated for awareness of FA supplementation to impart FA knowledge and benefits through health education or promotion, influencing the attitude and behavior of women during childbearing age.

Again, another unsatisfactory practices reported is that majority of the respondents avoid going for antenatal care at the health centers very often whenever they are pregnant similarly, majority of them 57 (34.8\%) do not always attend health education and awareness programs regarding maternal health in the community and clinic. Where almost three-quarter of the respondents $72(43.9 \%)$ do not consume alcohol before and during pregnancy only 51 (31.1\%) of them rarely avoid taking drug without prescription during pregnancy and lastly regarding practice of folic acid supplementation during pregnancy, more than half of the total respondents 88 (53.7\%) do not take folic acid as recommended during pregnancy. The level of knowledge and attitudinal disposition displayed by our study respondents has translated to the general unsatisfactory level of prevention practices demonstrated by these respondents and for any intervention to be effective in this region towards preventing adverse pregnancy outcomes the gaps in their knowledge of risk factors has to be filled and their negative attitudinal dispositions must be shaped to positivity. 


\section{Conclusion and Recommendation}

The findings from this present study on the level of knowledge, attitudes and adverse pregnancy outcomes prevention practice among women of reproductive age were average and evidently demonstrate the dynamic of the situations that predispose the women of reproductive age to the risk of adverse pregnancy outcomes. Hence, the reported unsatisfactory prevention practices call for sensitization and scaled-up health education in order to meet with the WHO's global strategy for ending all preventable deaths of women, children and adolescents and ensuring their well-being.

\section{Limitation of the Study}

This study was not free of limitations and the most standout limitation of this study was the designed instrument (refer to Appendix 1) which was completely in the English language making it difficult for some respondents to fully comprehend. Although the research assistants interviewed those participants in their local language based on their understanding of the instrument contents, considering the devoid of professional translation, it was likely to open room for bias.

Besides, since this study is a community-based survey, it is limited to reproductive-aged women outside the health facilities and might not give a broader representation of the general women population since some will be readily taking up ANC at health centers during the study period.

\section{Conflicts of Interest}

The authors declare no conflicts of interest regarding the publication of this paper.

\section{References}

[1] Victora, C.G., Requejo, J.H., Barros, A.J., Berman, P., Bhutta, Z., Boerma, T., Chopra, M., de Francisco, A., Daelmans, B., Hazel, E., et al. (2016) Countdown to 2015: A Decade of Tracking Progress for Maternal, Newborn, and Child Survival. The Lancet (London, England), 387, 2049-2059. https://doi.org/10.1016/S0140-6736(15)00519-X

[2] Alkema, L., et al. (2016) Global, Regional, and National Levels and Trends in Maternal Mortality between 1990 and 2015, with Scenario-Based Projections to 2030: A Systematic Analysis by the UN Maternal Mortality Estimation Inter-Agency Group. The Lancet, 387, 462-474. https://doi.org/10.1016/S0140-6736(15)00838-7

[3] World Health Organization (2015) Trends in Maternal Mortality: 1990 to 2015: Estimates by WHO, UNICEF, UNFPA, World Bank Group and the United Nations Population Division. World Health Organization, Geneva.

[4] Awiti, J.O. (2013) Preceding Birth Interval Length and Maternal Health in Kenya. University of Nairobi, Nairobi.

[5] Lee, A.C., et al. (2013) National and Regional Estimates of Term and Preterm Babies Born Small for Gestational Age in 138 Low-Income and Middle-Income Countries 
in 2010. The Lancet Global Health, 1, e26-e36.

https://doi.org/10.1016/S2214-109X(13)70006-8

[6] Blencowe, H., Cousens, S., Oestergaard, M.Z., Chou, D., Moller, A.B., Narwal, R., Adler, A., Garcia, C.V., Rohde, S., Say, L., et al. (2012) National, Regional, and Worldwide Estimates of Preterm Birth Rates in the Year 2010 with Time Trends since 1990 for Selected Countries: A Systematic Analysis and Implications. The Lancet (London, England), 379, 2162-2172. https://doi.org/10.1016/S0140-6736(12)60820-4

[7] Grimes, D.A., et al. (2006) Unsafe Abortion: The Preventable Pandemic. The Lancet, 368, 1908-1919. https://doi.org/10.1016/S0140-6736(06)69481-6

[8] United Nations Department of Economic and Social Affairs (2009) World Population Prospects: The Revision, Highlights. Working Paper, United Nations Department of Economic and Social Affairs, New York.

[9] Kassebaum, N.J., Bertozzi-Villa, A., Coggeshall, M.S., et al. (2014) Global, Regional, and National Levels and Causes of Maternal Mortality during 1990-2013: A Systematic Analysis of the Global Burden of Disease Study. The Lancet, 384, 980-1004. https://doi.org/10.1016/S0140-6736(14)60696-6

[10] Gardosi, J., et al. (2003) "Unexplained" Stillbirths: An Investigation of the Clinically Relevant Conditions at the Time of Fetal Death. American Journal of Obstetrics \& Gynecology, 186, S158. https://doi.org/10.1016/j.ajog.2003.10.354

[11] Kramer, M.S. (2003) The Epidemiology of Adverse Pregnancy Outcomes: McGill University Press Faculty of Medicine, Montreal. Journal of Nutrition, 133, 1592s-1596s. https://doi.org/10.1093/jn/133.5.1592S

[12] Kullima, A.A., Kawuwa, M.B., Audu, B.M., et al. (2009) Trends in Maternal Mortality in a Tertiary Institution in Northern Nigeria. Annual African Medical, 8, 221-224. https://doi.org/10.4103/1596-3519.59575

[13] Mairiga, A.G. and Salihi, W. (2009) Maternal Mortality at Specialist Hospital Bauchi, Northern Nigeria. East African Journal Medicine, 86, 25-30.

https://doi.org/10.4314/eamj.v86i1.46924

[14] Sadiq, A.A., Poggensee, G., Nguku, P., Sabitu, K., Abubakar, A., et al. (2016) Factors Associated with Adverse Pregnancy Outcomes and Perceptions of Risk Factors among Reproductive Age Women in Soba LGA, Kaduna State 2013. The Pan African Medical Journal, 25, 111. https://doi.org/10.11604/pamj.2016.25.111.8739

[15] Chandra, A., Martinez, G.M., Mosher, W.D., Abma, J.C. and Jones, J. (2005) Fertility, Family Planning, and Reproductive Health of US Women: Data from the 2002 National Survey of Family Growth. Vital Health Statistics, 23, 48. https://doi.org/10.1037/e414702008-001

[16] Johnson, K., Posner, S.F., Biermann, J., et al. (2006) Recommendations to Improve Preconception Health and Health Care United States.

[17] Eni-Olorunda, T., et al. (2015) Knowledge and Attitude of Mothers on Risk Factors Influencing Pregnancy Outcomes in Abeokuta South Local Government Area, Ogun State. European Scientific Journal, 11.

[18] Lynch, J., Smith, G.D., Hillemeier, M., et al. (2001) Income Inequality, the Psychosocial Environment, and Health: Comparisons of Wealthy Nations. The Lancet, 358, 194-200. https://doi.org/10.1016/S0140-6736(01)05407-1

[19] Finch, B.K. (2003) Early Origins of the Gradient: The Relationship between Socioeconomic Status and Infant Mortality in the United States. Demography Review, 40, 675-699. https://doi.org/10.1353/dem.2003.0033

[20] World Health Organization (2006) Management of Birth Defects and Haemoglobin 
Disorders: Report of a Joint WHO-March of Dimes Meeting, Geneva, Switzerland.

[21] National Population Commission (NPC) [Nigeria] and ICF International (2014) Nigeria Demographic and Health Survey 2013. NPC and ICF International, Abuja, Rockville.

[22] Tsegaye, B. and Kassa, A. (2018) Prevalence of Adverse Birth Outcome and Associated Factors among Women Who Delivered in Hawassa Town Governmental Health Institutions, South Ethiopia in 2017. Reproductive Health, 15, Article No. 139. https://doi.org/10.1186/s12978-018-0631-3

[23] Li, et al. (2019) Knowledge, Attitude and Practice Level of Women at the Periconceptional Period: A Cross-Sectional Study in Shaanxi China. BMC Pregnancy and Childbirth, 19, 326. https://doi.org/10.1186/s12884-019-2481-6

[24] Yang, W., Yang, L., Liu, L., Li, Y. and Wu, J. (2011) An Investigation and Analysis of KAP on Birth Defects of Periconceptional Women in Xi'an Areas. Chinese Journal of Woman and Child Health Research, 22, 36-39. (In Chinese)

[25] Alharbi, I.M., Alharbi, A.F., AlHarbi, S.M., Alharbi, H.M., Al Harbi, T.F., Alawaji, N.H. and Alluhaida, A.A. (2018) Knowledge and Attitude of Mothers on Risk Factors Influencing Pregnancy Outcomes in Qassim, Saudi Arabia: A Cross-Sectional Study. The Egyptian Journal of Hospital Medicine, 71, 3487-3491.

[26] Karlsen, S. and Say, L. (2011) The Relationship between Maternal Education and Mortality among Women Giving Birth in Health Care Institutions: Analysis of the Cross Sectional WHO Global Survey on Maternal and Perinatal Health. BMC Public Health, 11, 606. https://doi.org/10.1186/1471-2458-11-606

[27] Benegbi, M. (2007) 45 Years Later. Where Do We Stand? The Canadian Journal of Clinical Pharmacology, 14, 37-39.

[28] Bhalotra, S. and Van Soest, A. (2008) Birth-Spacing, Fertility and Neonatal Mortality in India: Dynamics, Frailty and Fecundity. Journal of Econometrics, 143, 274-290. https://doi.org/10.1016/j.jeconom.2007.10.005

[29] MOH (2007) Ghana Maternal Health Survey Report. Ghana Health Service Annual Report. Accra.

[30] Temel, S., Erdem, O., Voorham, T.A., Bonsel, G.J., Steegers, E.A. and Denktas, S. (2015) Knowledge on Preconceptional Folic Acid Supplementation and Intention to Seek for Preconception Care among Men and Women in an Urban City: A population-Based Cross-Sectional Study. BMC Pregnancy Childbirth, 15, 340. https://doi.org/10.1186/s12884-015-0774-y

[31] Olsen, S.F. and Knudsen, V.K. (2008) Folic Acid for the Prevention of Neural Tube Defects: The Danish Experience. Food and Nutrition Bulletin, 29, S205-S209. https://doi.org/10.1177/15648265080292S124 


\section{Appendix 1. Questionnaire}

Dear Respondent,

We are conducting a study on "Knowledge, Attitude and Practice of Adverse Pregnancy Outcomes Prevention among Women of Reproductive Age in Nassarawa Local Government Area, Kano State-Nigeria". Your participation in this study is very important as it would help us to better understand the health behavior processes that are responsible for improved quality of life for you. We desire most importantly that you respond truthfully and honestly to the best of your ability to all the items in the questionnaire. Please note that the completion of this questionnaire is entirely voluntary. All information gathered as a result of your participating in this study will be treated with utmost confidentiality.

Kindly respond to each statement as it agrees with you. Your honest answer will be highly appreciated. Agreeing to respond to the items imply that you have given your consent to participate in the study. Thank you.

Yours Faithfully,

AFOLABI ISMAIL B.

Date: / /

Serial no:

\section{Section A: Demographic Characteristics of Respondents (Please Tick where Applicable)}

1. Age at last birthday; years

2. Marital Status: Married [ ];

3. Religion: Islam [ ];

Divorced [ ];

Widowed [ ]

4. Educational Attainment:

; Christian [ ];

Others Please Specify:

Non-Formal [ ]; Primary [ ]; Secondary; [ ];

Post-Secondary (Vocational) [ ]; University [

\section{Section B: Knowledge on the Risk Factors Influencing Adverse Pregnancy Outcomes}

Kindly tick $[\sqrt{ }]$ in the appropriate column to indicate how your knowledge corresponds with regards to the subject matter as reflected in the statements below using the following key: SA = Strongly Agree; $\mathbf{A}=\mathrm{Agree} ; \mathrm{D}=\mathrm{Disagree}$ and $\mathrm{SD}=$ Strongly Disagree.

\begin{tabular}{|c|c|c|c|c|}
\hline Statement for considerations & SA & A & $\mathrm{D}$ & SD \\
\hline 5. Malnutrition in pregnancy could result in smallness of the baby, abortion or oth & & & & \\
\hline $\begin{array}{l}\text { 6. Pregnancy at younger age below } 15 \text { years do not often result in having children } \\
\text { Developmental Disabilities and pose risk of caesarean section at birth }\end{array}$ & & & & \\
\hline 7. Inadequate pre-natal care would cause death of the mother due to difficulties du & & & & \\
\hline 8. Alcohol consumption cannot lead to reduced birth size of the baby & & & & \\
\hline 9. Inadequate maternal education can result in poor deliveries & & & & \\
\hline 10. Drug abuse at early stage of pregnancy can result in brain damage of the baby & & & & \\
\hline
\end{tabular}

\section{Section C: Attitudes toward Adverse Pregnancy Outcomes Prevention Practices}

Kindly tick $[\sqrt{ }]$ in the appropriate column to indicate how your attitude corresponds with regards to the subject mat- 
ter as reflected in the statements below or your opinion using the following key: SA = Strongly Agree; $\mathbf{A}=$ Agree; $\mathbf{D}=$ Disagree and SD = Strongly Disagree.

\begin{tabular}{|c|c|c|c|c|}
\hline Statements to be considered & SA & A & D & SD \\
\hline 11. I do not see anything wrong in being pregnant every year or in quick succession & & & & \\
\hline $\begin{array}{l}\text { 12. I will readily undergo Caesarean section if need be in order to avoid complications } \\
\text { during delivery }\end{array}$ & & & & \\
\hline 13. My culture does not see anything wrong in having children as early as age 15 & & & & \\
\hline $\begin{array}{l}\text { 14. I do not think going for antenatal checkup is necessary hence I have my babies in the } \\
\text { church or mosque }\end{array}$ & & & & \\
\hline 15. I do not see the need for education as a factor for safe delivery & & & & \\
\hline $\begin{array}{l}\text { 16. I do not have any problem as regards taking folic acid before and during pregnancy } \\
\text { as recommended }\end{array}$ & & & & \\
\hline
\end{tabular}

\section{Section D: Adverse Pregnancy Outcomes Prevention Practices}

Kindly tick $[\sqrt{ }]$ in the appropriate column to indicate how your prevention practices correspond with regards to the subject matter as reflected in the statements below or frequency of actions using the following key: NA = Not at All; $\mathbf{R}=$ Rarely; $\mathbf{O}=$ Occasionally and $\mathrm{VO}=$ Very Often .

\begin{tabular}{|c|c|c|c|c|}
\hline Statements to be considered & NA & $\mathbf{R}$ & $\mathrm{O}$ & VO \\
\hline \multicolumn{5}{|l|}{ 17. I avoid going for antenatal care at the health centers whenever I am pregnant } \\
\hline \multicolumn{5}{|l|}{$\begin{array}{l}\text { 18. I attend health education and awareness programs regarding maternal health in the } \\
\text { community and clinic }\end{array}$} \\
\hline \multicolumn{5}{|l|}{ 19. I do consume alcohol before and during pregnancy } \\
\hline \multicolumn{5}{|l|}{ 20. I avoid taking drug without prescription during pregnancy } \\
\hline $\begin{array}{l}\text { 21. I am not used to taking Folic acid as recommended during pregnancy to prevent } \\
\text { unwanted pregnancy }\end{array}$ & & & & \\
\hline
\end{tabular}

Thank you for your responses. 